attendance of students at any advanced courses at a designated college of advanced technology outside the area in which they reside and also in respect of attendance at any other course in a designated college or elsewhere, except where an authority finds it desirable to require prior consent. The Minister and the regional advisory council concerned should be informed of the exceptions. Automatic consent may be withdrawn if, in the authority's opinion, the student's attendance or progress is unsatisfactory. Local education authorities should review the composition of governing bodies of technical colleges to ensure that they include appropriate representation of authorities from whose areas substantial numbers of out-county students are drawn.

\section{International Radio Consultative Committee}

THE eighth plenary assembly of the International Radio Consultative Committee (C.C.I.R.) was formally opened in Warsaw on August 9, to study various technical problems encountered in the practice and development of radio communication, with the view of making recommendations to be submitted to the International Telecommunications Union (I.T.U.). The work of the Committee is organized under fourteen study groups, which are meeting during the period August 10-31, after which the full assembly will discuss the various recom. mendations and study programmes with the view of their adoption as a guide to future progress in the radio field. The United Kingdom delegation is led by Captain C. F. Booth, assistant engineer-in-chief, General Post Office, accompanied by seven othe:delegates of the Post Office staff, and one each from the Department of Scientific and Industrial Research and the Ministry of Supply. The delegation also includes technical advisers, of the Radio Industry Council and representatives of the organizations operating radio services in Britain. Two members of the delegation are the international chairmen of study groups, namely, Dr. R. L. Smith-Rose (Study Group V), on tropospheric wave propagation, and Mr. H. Stansby (Study Group IX), which deals with general technical questions.

Among the subjects of particular scientific interest under discussion are those of radio wave propagation over the ground and through the troposphere and ionosphere, atmospheric noise in various parts of the world, radio time signals and standard frequencies and various aspects of broadcasting and television. Adequate liaison arrangements have been established between the International Radio Consultative Committee and the International Scientific Radio Union (U.R.S.I.) for the study of subjects of mutual interest, with the general objective of improving the efficient and economical use of the redio-frequency spectrum for all practical and scientific purposes.

\section{World Resources in the Immediate Future}

THE spring issue of Progress, the magazine of Unilever, Ltd., includes the last of a series of articles surveying world resources which Sir Solly Zuckerman has edited during the past five issues. The series was introduced by Sir Solly himself in the spring issue of 1955 with an article in which he outlined broadly the problem presented by the rapid growth of world population and the consequent growing demand for capital and consumer goods and higher standards of living. In following articles $\mathbf{M}$. John considered, first, world supplies of power and water and then those of land and food, and finally of raw materials, setting out in broad terms the main material considerations that are likely to determine the development of industry over the next two or three decades. In this final article on the social and political aspects, Sir Solly Zuckerman agrees that no shortage is likely to develop capable of defeating human ingenuity; but he believes that the unequal division of resources between 'have' and 'have-not' countries is the core of a social challenge steadily growing more urgent with the rapid increase in the populations of the under-developed countries of the Eastern world. The price of peace may well be the sharing of resources, and if the British are not to lose by the sharing they must remain constantly alert to the challenge of new industrial technologies and to the possibilities of creating greater wealth.

\section{The Imperial Forestry Institute, Oxford : Report} for 1954-55

THE thirty-first annual report for 1954-55 of the Imperial Forestry Institute, Oxford, to which is attached the University School of Forestry (pp. 32; from the Institute, 1956), points out that in 1955 the School celebrated its fiftieth year, having been brought to Oxford by Dr. Schlich when the Royal Indian Engineering College, Coopers Hill, was closed in 1905. The Forest Herbarium, though still housed in the Botany Department, has now been transferred back to the School of Forestry. The number of students attending courses during the year was fiftyeight. Fourteen were successful in the examination for their forestry degrees; and of these, two were Colonial forest probationers who returned to their Colonies, two obtained posts in the Colonial Forest Service, one returned to Pakistan to join the Forest Service there, a South African obtained a post in the Northern Rhodesian Forest Department, and another two went to Canada before returning to South Africa. One government scholar from each of Kenya and Jamaica returned to join their respective forest departments. One graduate joined the Oxford University Expedition to Borneo as botanist, and four joined up for National Service. This enumeration furnishes ample eridence that the Institute has fully justified its inauguration, the more so since many parts of the British Colonies will in future be more or less dependent upon it for maintaining the requisite professional knowledge in the staffs of their departments. The forest officers' course at the Institute was attended by twelve officers of the forest services of various Colonies. The sections dealt with in the report are sylviculture, ecology, tree physiology, forest botany, forest pathology, forest entomology, mensuration, aerial surveys, statistics, forest economics, forest law, Colonial forest administration, forest protection, surveying and the library.

\section{Agricultural Research in India}

A BRIEF account of research and agriculture in India under the Second Five-Year Plan is given in the April number of Science and Culture by M. S. Randhawa. Out of Rs. 350 crores for the Central and State research and development schemes, Rs. 38 crores is for direct expenditure by the Central Government. The production and distribution of nitrogenous fertilizers is to be increased to three times the present level of 600,000 tons a year, and a scheme is proposed for the distribution of improved seeds through a network of seed farms, each serving a group of a hundred villages. Large-scale developments are proposed for cattle, sheep and poultry, 